\title{
CMA GC: No new federal funding promised for Health Accord
}

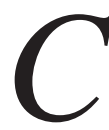

$M A J$ is reporting from the 149th Annual Meeting and General Council of the Canadian Medical Association (CMA), being held in Vancouver Aug. 21-24. Issues discussed this year include a new Health Accord, vaccination and medical professionalism.

\section{No new federal funding promised for Health Accord}

A federal cash injection won't fix Canada's health system, said Health Minister Dr. Jane Philpott in an address to CMA General Council on Aug. 23.

"This year the Canada Health Transfer reached a historic high of over $\$ 36$ billion, but I am firmly convinced that we have an obligation as a federal government to do more than simply open up the federal wallet," Philpott said.

Upcoming negotiations of a new health care accord between the federal government, provinces, and territories present a "rare opportunity" to reshape the system to meet the demands of an aging population, she added. However, Philpott stopped short of making any new funding promises beyond existing commitments in home care, health care information and indigenous health.

Read the full article

\section{CMA votes to stop nonmedical exemption for vaccination}

Eliminating nonmedical exemption from vaccination for school-age children could backfire, leading to even more vaccine hesitancy and refusal, argued some delegates at the CMA annual meeting. Despite vocal opposition, a motion narrowly passed in support of

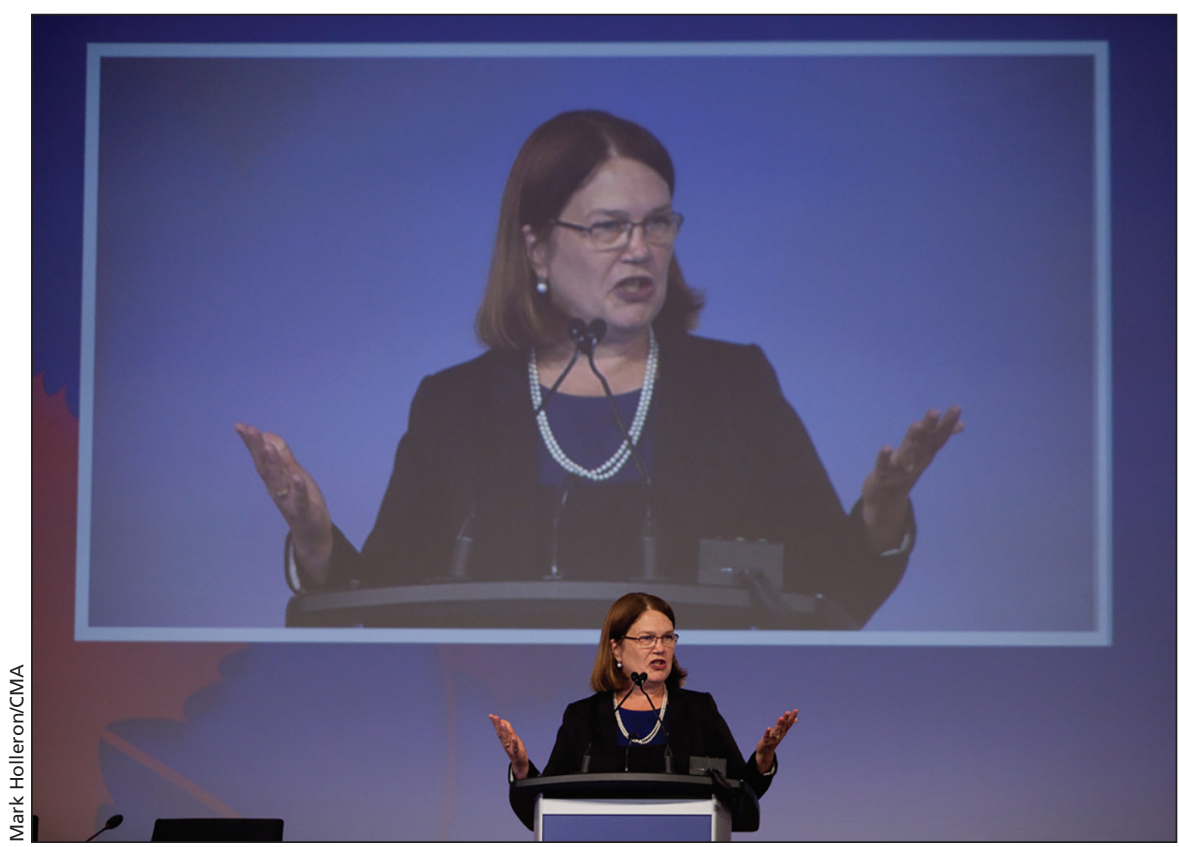

Federal Health Minister Dr. Jane Philpott sidestepped questions about new funding under a renegotiated Health Accord with the provinces and territories.

the elimination of nonmedical exemption for vaccination in Ontario, New Brunswick and Manitoba, where children must be vaccinated in order to attend school.

The topic has been debated since Britain introduced nonmedical exemption in 1889, said mover Dr. Tommy Gerschman of British Columbia. "After more than 200 years, we need to stop worrying about a backlash."

Read the full article

\section{Unity needed in challenging times for medical profession}

Has the medical profession lost its soul? This question was posed by a retiring doctor at an event in New Brunswick, as he lamented the future of medicine. In the audience that evening was Dr. Cindy Forbes, who is finishing her year as president of the CMA. The question stung, and it stuck with her for weeks. Ultimately, however, the answer became clear to her.

"I do not believe that we are a profession that has lost its soul," Forbes said during her valedictory address. "If anything, I believe that the values that are reflected in the oath that we all take, the values that brought us to this profession in the first place, are as strong as they have ever been." Read the full article

— Lauren Vogel, CMAJ

CMAJ 2016. DOI:10.1503/cmaj.109-5319 